\title{
Erratum to: 2017 Colorado alphaherpesvirus latency society symposium
}

\author{
Nicholas L. Baird ${ }^{1}$. Randall J. Cohrs ${ }^{1,2}$
}

Published online: 28 September 2017

(C) Journal of NeuroVirology, Inc. 2017

Erratum to: J. Neurovirol. (2017) 23:642-655

https://doi.org/10.1007/s13365-017-0559-3

On page 650 , the institutional affiliation of Dr. Werner J.D. Ouwendijk was incorrectly listed as Freie Universitaet Berlin. It should instead be Erasmus MC, Rotterdam, The Netherlands.

The online version of the original article can be found at https://oi.org/ $10.1007 / \mathrm{s} 13365-017-0559-3$

$\triangle$ Randall J. Cohrs

randall.cohrs@ucdenver.edu

1 Department of Neurology, University of Colorado School of Medicine, 12700 E. 19th Ave, Box B182, Aurora, CO 80045, USA

2 Department of Immunology and Microbiology, University of Colorado School of Medicine, 12700 E. 19th Ave, Box B182, Aurora, CO 80045, USA 